\title{
NINA BOURAOUI: DE GARÇON MANQUÉ A POUPÉE BELLA, ITINERARIO VITAL DE UNA CONSCIENCIA
}

\author{
NINA BOURAOUI: FROM GARÇON MANQUÉ TO POUPÉE BELLA, \\ LIFE ITINERARY OF A CONSCIOUSNESS
}

\author{
Montserrat SERRANO MAÑÉS \\ Universidad de Granada \\ mserrano@ugr.es
}

\begin{abstract}
Resumen: La autobiografía, estrechamente ligada con el autor/autora, lleva implícita la identidad sexual. Aunque es difícil evitar las especificidades femeninas, no debemos obviar la posible universalidad de esas obras, ni las particularidades propias de cada autora. En Bouraoui observamos un tratamiento particular del relato autobiográfico-autoficcional y del diario íntimo: el triple edificio literario de Garçon manqué, Poupée Bella y Mes mauvaises pensées, son variantes de estos tipos de escritura. De GM, autobiografía-autoficción, y PB, diario íntimo exhibicionista, pasamos a la novela MMP, teñida de datos biográficos. La biografía, utilizando diversas formas del discurso autobiográfico, es una constante de su escritura.
\end{abstract}

Palabras clave: Nina Bouraoui. Autobiografía. Autoficción.

Abstract: The autobiography, closely linked with the authors, implies sexual identity. Although it is difficult to avoid female specificities, we must not ignore the possible universality of such works, or the particularities of each author. Bouraoui observed a particular treatment of the autobiographicautofictional story and the intimate diary: triple literary building Garçon manqué, Poupée Bella and Mes mauvaises Pensées, are variants of these 
types of writing. After GM, autobiography-autofiction, and PB, intimate diary exhibitionist, we analyse the novel MMP, tinged with biographical data. Biography, using various forms of autobiographical discourse, is a constant in her writing.

Key Words: Nina Bouraoui. Autobiography. Autofiction.

\section{DE LA AUTOBIOGRAFÍA, LA AUTOFICCIÓN Y EL DIARIO}

Cuando abordamos la escritura autobiográfica, aplicada a mujeres, la tentación de dejarse abducir por los Gender Studies es grande. Ciertamente, la autobiografía está estrechamente ligada a la identidad de su autor/autora, por lo que lleva, también, el signo de su identidad sexual. Pero aunque es difícil no caer en las especificidades femeninas, no debemos dejar al margen lo que pueda haber de universal en esas obras, ni las particularidades propias de cada autora. En el auge de la escritura femenina de fines del siglo XX se observa cómo la mujer encontró en ese campo su manera de "decirse"; gesto autobiográfico en la que lo vivido, expresado de manera franca, en muchos casos rayana en la pornografía, ha dado paso a una escritura siempre explícita, pero explorando nuevos caminos de expresión: tercera persona, historias ajenas ficcionales o propias, abordadas desde una perspectiva más alejada, son cada vez más frecuentes, sin que desaparezca la sinceridad casi impúdica, ni la falta de respeto a los tabúes.

Las formas que adopta la escritura de sí mismo son múltiples. $\mathrm{Ph}$. Lejeune ha pasado del estudio de la autobiografía al estudio del diario íntimo ${ }^{1}$. Éste reposa también sobre un pacto que obliga al autor a ser absolutamente sincero. Pero cabe preguntarse si ello es posible: la estructura del diario, más que la autobiografía, implica la nula distancia entre lo contado y lo ocurrido. Se trataría de una escritura inmediata, sin pasar por el filtro del recuerdo, como sucede en una autobiografía.

La boga de la autoficción nos permite, como lectores, insinuar nuestros recelos sobre la posibilidad de decirse. Quizá la mezcla de

1. Lejeune (2013: 45) confirma la idea de "pacto autobiográfico", considerando que la autobiografía es tanto un modo de lectura como un tipo de escritura, "un effet contractuel historiquement variable". 
verdad biográfica y ficción sea un modo de ofrecer una aportación teórica personal, aunque no exclusiva. El punto de vista selectivo que implica la autoficción puede suponer una ruptura con el aspecto autobiográfico, y también implicar nuevas maneras de expresarse.

En el caso de Nina Bouraoui, podemos observar el tratamiento acordado al relato autobiográfico $-\mathrm{O}$ autoficcional: las fronteras son inestables- y al diario íntimo: en Garçon manqué, Poupée Bella y Mes mauvaises pensées nos encontramos con variantes de estos tipos de escritura $^{2}$. Si GM puede considerarse una mezcla de autobiografía y autoficción, PB refleja una transcripción puntual y dispersa, que quiebra lo que se considera proyecto autobiográfico ${ }^{3}$.

Autoficción o relato real, estamos ante una escritura que podemos calificar de identitaria, y por tanto, incluida en lo que Lejeune denomina autobiografía ${ }^{4}$ : textos en los que el autor se compromete a decir la verdad sobre sí mismo. Y si algo caracteriza la escritura de Bouraoui es su dualidad. En su obra se entrecruzan su problema identitario -dualidad cultural y genérica- con la transgresión de la escritura. En estos libros, descubriéndose por la palabra, la autora exhibe los tabúes franqueados para llegar a su aceptación. El que haya abandonado el territorio de la autobiografía tras MMP nos lleva a pensar que esa dolorosa etapa ha concluido ${ }^{5}$.

\section{GARÇON MANQUÉ O EL ARTE DE RELATAR RECUER- DOS}

GM, escrito en primera persona, se presenta como narración autobiográfica-autoficcional, una exploración identitaria en la que, sin embargo, queda abierta una puerta hacia la ficción: los límites entre lo contado y lo no dicho por la narradora son siempre indecisos; esa inestabilidad de la realidad transcrita muestra su deseo de mantener

2. Los títulos de las obras se señalarán con las abreviaturas siguientes: Garçon Manqué: GM; Poupée Belle, PB; Mes Mauvaises pensées: MMP.

3. En el caso de Bouraoui, como en el de tantas escritoras, debemos tener siempre presente que el problema fundamental de la autobiografía es averiguar no cómo se escribe, "mais pourquoi l'écrivain passe à l'acte" (Hermetet \& Paul, 2016: 16).

4. Como indica Lejeune (2013), es esencial el aprendizaje de saber decir "yo" y construirse una historia, con mitos fundadores y un sistema de valores propios.

5. A propósito de su novela Avant les hommes, aparecida en 2007 , la autora dice haber pasado página del yo autobiográfico: "J'ai tourné la page du 'je' autobiographique". 
secretos momentos especiales, sin esconder ni desmentir la vertiente autobiográfica: la onomástica y la cronología permiten identificar protagonista y autora, asentándose en una construcción narrativa basada en la dualidad: nominativa, espacial y sexual.

\subsection{Forma y espacios en Garçon manqué}

Aparentemente, GM es un relato clásico, autobiográfico y lineal, con un narrador homodiegético que cuenta la historia en primera persona; sin embargo, en lo referente a la escritura hallamos frases en presente entrecortadas y nerviosas, que causan una sensación de fragmentación. Bouraoui parece sentir que sus dos espacios vitales, Argel y Rennes, son opuestos; su único vínculo es el mar, y momentos privilegiados de la memoria ligados al tiempo pasado en la playa. El marco aparentemente estable deja de serlo cuando la multiplicidad de nombres de la protagonista impide la cristalización del relato, subrayando su búsqueda identitaria.

El espacio, dividido en dos partes, se corresponde en líneas generales con dos tiempos cronológicos alternos y escrituralmente equilibrados: Alger, Rennes. Dos breves epígonos -Tivoli, Amine-, cierran el relato, construido aparentemente a partir de momentos enterrados en la memoria. Bouraoui yuxtapone constantemente espacios abiertos y libres, con otros cerrados seguros: la casa, la habitación o el coche; frente a ellos, los espacios prohibidos: la calle, la ciudad. Ese yo subraya la distancia existente entre el yo narrado y el yo narrador ${ }^{6}$. Pero los lugares cerrados, protectores, no son totalmente positivos. Recordando La Voyeuse interdite, la casa se percibe como prisión, y la habitación como lugar íntimo en el que puede construirse.

\subsection{Líneas temporales y memoria}

Aunque la cronología es lineal, la memoria, siempre débil, decolora el relato. Sentimos momentos detenidos en el flujo de los recuerdos: mismo

6. Según G. Cordesse, "Cette distinction essentielle entre héros et narrateur, ou Je-narré et Jenarrant, réintroduit bien un certain jeu entre ces deux positions; le Je-narrant est séparé du Je-narré par le temps (de quelques heures dans un 'journal intime' à plusieurs années dans les 'mémoires'), il est supérieur au Je-narré grâce à la connaissance des événements ultérieurs, et peut-être à l'expérience acquise ou à la sagesse rétrospective" (1988: 490). Cf. también J.M. Adam (1985: 178). 
mar, mismo baño, mismos juegos... El presente deviene perdurable. La cadencia del pasado se refleja en instantes claves: la fecha de su llegada a Argelia desde Rennes o el comienzo de la violencia, cuando en 1970 abandona el país, que queda inmovilizado en el tiempo de la memoria:

Je deviendrai un corps qui attend. Ici le temps est infini. Il est entêtant. C'est une prison. Il est contre les hommes. Il est à leur insu. Chaque jour est une violence. Chaque instant est une explosion. Dès 1970 la violence algérienne est dans la rue. Elle vient du temps immobile. Elle est dans ces corps qui cherchent. Qui marchent en cercles (GM: 3940).

Un cierre espacial gradual, que implica espacios hasta entonces seguros, anuncia el fin de sus años argelinos. En el hilo de la memoria, las proyecciones hacia el futuro de su nueva vida devienen interrogaciones vitales -"Qui serai-je en France? Où aller? Quels seront leurs regards?" (GM: 20). La acuidad de su mirada hace que en sus interpelaciones al amigo de infancia -si acaso fuera real-, sea capaz de relatar el futuro que les espera, cuando para el yo narrador ese futuro pertenece ya al pasado. Amine convierte a ese narrador en ficticio, al ser el lector el verdadero receptor. Al borrar su identidad, la narradora borra la suya propia: yo narrador y yo narrado se codean en ese decir el futuro del otro, que parecen más bien sus vivencias. Ambos se confunden en la voz de papel, que muestra cómo los sentimientos y su amistad infantil son un todo.

\subsection{Tiempos y voz}

El uso de la primera persona y del presente $^{7}$ enraíza el relato en la autobiografía ${ }^{8}$, y pone de relieve la búsqueda perenne de la narradora. El juego de oposiciones basado en la dualidad -espacial,

7. J. Milly (1992: 131) destaca cómo el relato en presente da al lector la impresión de una mayor actualidad de la historia, siendo un procedimiento adoptado a menudo por los escritores en los textos que transponen sus recuerdos y los vaivenes entre presente y pasado, permitiendo explotar "toutes les ressources de la langue en matière de temporalité".

8. Según D. Cohn (1981: 196-197), "Dans le roman autobiographique, le temps qui suscite les réflexions les plus intenses est plus souvent le présent que le passé, si bien que les esprits les plus mémorables que le genre a produit appartiennent au moi narrateur plutôt qu'au moi de l'histoire". 
identitaria-, la elección escritural, descubren a una Bouraoui que se sabe portadora de una identidad fracturada. En esa cohabitación interna intenta construirse un nuevo yo: Yasmina, convertida en Nina, tratará, gracias al quimérico Amine, convertirse en su doble. Por la escritura, pasado y presente se funden así en las mismas identidades:

Je passe de Yasmina à Nina. De Nina à Ahmed. D'Ahmed à Brio. [...] Je ne sais pas qui je suis. Une et multiple. Menteuse et vraie. Forte et fragile. Fille et garçon. Mon corps me trahira un jour. [...]Je retiendrai Nina, de force, comme un animal sauvage (GM: 60).

En tensión constante entre las dos orillas, el único punto de anclaje seguro es la escritura. Desde el principio, con continuas alusiones, Bouraoui apunta a ese espacio escritural como lugar de libertad para construirse. Su finalidad, desde el silencio doloroso de sus primeros años, sería así poder inscribirse en el mundo escribiendo:

Oui, je me prends pour un homme. Mais un homme qui voit. Un homme qui sait. Toi tu es empêché par ton enfance. Ton inconscience. Ce rêve fera écrire. Mon secret. Écrire. Me sauver du monde. De ton regard. Perdre Alger. Perdre l'Algérie. C'est impossible. Mais ça arrivera, Amine (GM: 86-87).

Las páginas dedicadas a sus veranos franceses afirman su interminable exploración personal. La relación con su familia de Rennes se incluye en largas analepsias, en ocasiones fragmentadas. Esos veranos que se repiten y superponen no contradicen lo expresado en la primera parte: deseo de afirmación, escritura como espacio de libertad. Mar y playa siguen siendo puntos de referencia indispensables. La felicidad que le aporta el mar es inseparable de la felicidad de sentirse querida:

C'est un bain heureux. L'eau est chaude. [...] Puis je remonte l'escalier de pierre, un peu effrayée. Mais je ne dis rien. Ma grand-mère m'enroule dans une serviette-éponge. Elle frotte de toutes ses forces. Contre la mer qui se retire 
déjà. Contre ses courants. Contre la nuit qui tombe sur la plage engloutie. [...]Je n'ai plus peur. Je suis aimée (GM: 168).

Pese a todo, el pasado rebrota superponiéndose al tiempo contado. Los cuerpos blancos tendidos en la arena evocan momentos sepultados en su memoria, y hacen que establezca una comparación con los cuerpos masacrados en Argelia:

Une plage froide et souvent trempée. [...]. Avec tous ces corps allongés. Qui attendent le soleil. La couleur. Avec ce désespoir d'être blanc. En été. Ces corps alignés. Ou en escalier. Sur le ventre. Sur le dos. Assis. En biais. Ces corps immobiles. Figés dans leur dernier geste. Qu'on pourrait croire morts, vus de loin. Morts et nus. Comme tous ces corps découverts après le massacre du village de B. Des corps d'enfants. Coupés en deux. Des corps de femmes tailladés sur la longueur. Comme une fermeture Éclair (GM: 154).

La casa, espacio seguro, se amplifica convirtiéndose en refugio. Asimilándose al granero con toda su carga simbólica ${ }^{9}$, el piso superior guarda la memoria de su madre. Nido protector, la casa tiene el poder de borrar los miedos y protege de la muerte, que merodeaba entre los muros argelinos: "Seule la maison existe. Seule la maison irradie. Comme si je ne l'avais jamais quittée. Elle devient ma maison" (GM: 118).

El uso predominante del presente afirma el carácter repetitivo de los recuerdos. Como lectores, accedemos al relato de los veranos que se suceden con una cadencia iterativa que no borra, sin embargo, los momentos lejanos del yo narrante (GM: 146). Los límites cronológicos de este bloque son tenues. El encuadre espacial incluye regresos al pasado,

9. Durand (1969: 275-281) y Bachelard (1981: 23-50) se refieren a este aspecto. Si Bachelard le dedica un capítulo - "La maison. De la cave au grenier. Le sens de la hutte"-, para Durand "Le grenier, malgré son altitude, est musée des ancêtres et lieu de retour aussi énigmatique que la cave. Donc, 'de la cave au grenier', ce sont toujours les schèmes de la descente, du creusement, de l'involution et les archétypes de l'intimité qui dominent les images de la maison”. Es interesante ver la diferencia que se establece entre la casa paterna, que pasa desapercibida, y la materna, que Bouraoui describe minuciosamente, confirmando la idea de Bachelard sobre lo que él denomina "la maternidad de la casa" (1981: 57). 
focalizados en los personajes del núcleo familiar; es el modo, también, de incluir en esta su biografía la biografía del antes, la historia de sus padres, como si formara parte de su memoria personal, en un hacer literario que recuerda la no-autobiografía de Yourcenar.

Las huidas hacia el futuro relacionadas con el tiempo restituido por la escritura se incardinan en un eje discursivo particular: el del desenraizamiento, el de una identidad negada por la mirada de los otros: hija de argelino y de francesa, resultado de una pareja mixta. La concatenación de movimientos temporales (analepsias-prolepsis, pasado-futuro) crea una cadencia que estabiliza en cierto modo la cronología, y la narradora sitúa los hechos vividos por sus padres al mismo nivel temporal que los suyos propios:

Un jour, j'entendrai, à l'arrêt du bus numéro 21, une femme dire en regardant mon père: Il y a trop d'Arabes en France. Beaucoup trop. Et en plus ils prennent nos bus. Ses mots et mon silence. Cette incapacité à répondre. À hurler. Cet homme est mon père. Respectez-le ou je vous insulte. Respectez-le ou je vous frappe. Respectez-le ou je vous tue. [...] Mais rien. Mon silence. Mon père et mon silence. Lui non plus il ne dira rien (GM: 130).

Bouraoui parece querer forjarse una identidad contra las actitudes de quienes no aceptan la diferencia. La fragilidad de su yo desaparece en su afirmación final -“Je n'ai pas honte d'être aussi algérienne. [...] J'étoufferai mon côté français" (GM: 170)-, en su lucidez para rechazar toda representación que minimice su identidad cultural. Pero antes debe pasar por sus identidades argelinas reprimidas, por el rechazo de su yo inventado, ese Ahmed que ahora esconde -"Dans cet été français je cache profondément Ahmed" (GM: 179).

La gradación elegida se apoya en el yo narrador, que sustituye al yo de la acción. Cuando da preferencia al tiempo ulterior, reenvía el relato hacia un futuro ya inscrito en su realidad. Las alusiones a sus libros son una respuesta a sus miedos y una negación de sus silencios: "Bien sûr qu'il ne fallait pas répondre. Je trouverai mieux. Je l'écrirai. C'est mieux, ça, la haine de l'autre écrite et révélée dans un livre. J'écris" (GM: 132). En el mismo sentido, los monólogos interiores expresan su voluntad de escribir 
como manera de refugiarse de sus miedos, como una ruptura de su silencio protector, y abarcan el presente y el futuro de la escritora ${ }^{10}$, reflejando su profundo desasosiego. Pero, lúcidamente, establecida firmemente en el presente, es capaz de aunar ironía y amargura; la escritura brota entonces como el arma de defensa elegida:

Cette génération, ni vraiment française ni vraiment algérienne. [...] Ces enfants fantômes. Ces prisonniers. Qui portent la mémoire comme un feu. Qui portent l'histoire comme une pierre. Qui portent la haine comme une voix unique. Qui brûlent du désir de vengeance. Moi aussi j'aurais cette force. Cette envie. De détruire. De sauter à la gorge. De dénoncer. D'ouvrir les murs. Ce sera une force vive mais rentrée. Un démon. Qui sortira avec l'écriture (GM: 129).

\subsection{Tivoli y Amine, los epígonos}

Tivoli, primera y breve conclusión de GM, se abre sobre otro horizonte, un lugar de posible transformación. La alternancia del je y el nous, las alusiones a la presencia de su hermana, tienen el efecto benéfico del olvido y desaparición de la barrera que le impedía reconstruir su identidad. Con el uso del pasado durativo, los recuerdos se transforman en elementos positivos para el descubrimiento de su nuevo yo. Sin trabas de ningún tipo, es feliz de ser ella misma, y de poder sentir su cuerpo libre, bajo la mirada sin prejuicios de los demás: "Je suis devenue heureuse à Rome. [...] Je venais de moi et de moi seule" (GM: 185).

Sin embargo, desde esa apertura positiva, Bouraoui se adentra de nuevo en lo más profundo de su ser, en el segundo epílogo de dos páginas titulado Amine. Aunando escritura autobiográfica y epistolar, ambas reflejos del yo más profundo, Bouraoui incluye una carta redactada en el presente de la escritura y dirigida a Amine, personaje de su pasado. Especie de bisagra entre pasado-presente, esa carta aparentemente cierta reaviva el juego confuso de identidades, sumiendo en la inestabilidad toda

10. "Moi aussi je l'aurais, cette force" (GM: 132): El uso aislado de un tiempo relativo del pasado, el condicional en -rais, que Milly llama "futur du passé” (1992: 127), reafirma la superposición temporal. 
frontera cronológica o espacial, y aboliendo las distancias entre ficción y realidad. La carta, cuyo verdadero destinatario parece ser el lector, relata recuerdos, al tiempo que se asoma al porvenir, y esa percepción del futuro la aleja definitivamente de su pasado. Finalmente, revela también, junto a la fuerza de la escritura, la importancia de ese doble sexual, ficticio o real, que se funde con la también doble identidad geográfica de Bouraoui:

Sans le savoir, tu m'as donné parfois la force d'écrire. Par ton souvenir, si plein, si constant. [...]. Il restera toujours une trace de toi, Amine. Sur ma peau. Un petit tatouage bleu, comme le ciel d'Alger. Il restera toujours quelque chose de nous, Amine. Dans nos rêves. Dansnotreforce. Danscettejoie à retrouver. Dans cette odeur algérienne qui revient comme par miracle à chaque printemps français (GM: 188-189).

Siempre a través de la exploración identitaria, tan visible en GM, Bouraoui continúa su búsqueda personal y profundiza en datos autobiográficos, en libros a veces desconcertantes. PB es el relato de la aceptación de sí misma, mientras que en MMP regresa a su pasado argelino, y da la impresión de que, por fin, ha hallado la calma y la paz en el amor y la escritura. La forma escritural varía de un libro a otro, pero manteniéndose siempre en ese espacio del decirse que es la escritura autobiográfica. Si en GM onomástica y cronología permiten la identificación autobiográfica entre protagonista y autora, la construcción narrativa subraya continuamente la dualidad. Las elecciones clásicas de la escritura son los de una narración autobiográfica de desarrollo lineal, con un autor homodiegético que relata en primera persona. Pero esa escritura afilada, que evoca casi fotográficamente los recuerdos con frases cortas, crea una sensación de fragmentación.

\section{POUPÉE BELLA, LA AMBIGÜEDAD DEL DIARIO ÍNTIMO}

Al autobiográfico-autoficcional GM le sigue el relato deslavazado de PB. Y a las frases cortas, cortantes incluso, de esta suerte de diario íntimo, le sigue, para concluir el ciclo autobiográfico, el relato interminable de MMP. En los tres casos Nina Bouraoui, sin dejar las orillas de la escritura 
del yo, se regodea en dejar al lector un post-gusto, como el de un buen vino de ambigüedad formal: son relatos, novelas, autobiografías, autoficción ${ }^{11}$ ? Solo la escritura parece ser un ancla. De un libro a otro, las pistas autobiográficas se repiten. Este triple edificio literario en el que nos hemos apoyado, se yergue y mantiene gracias a la reintegración del pasado. La exploración de su yo está sembrada de puntos de referencia inamovibles: onomástica, cronología, datos personales y familiares... Esas referencias le permiten afirmarse como sujeto, y contar con un espacio más allá de la escritura misma.

En PB subyace el deseo de exponerse. Al elegir la forma de diario íntimo, destinado en realidad a un público potencial -la mentira de la escritura autobiográfica está más presente que nunca-, Bouraoui revela su yo profundo, ese que debiera quedar encerrado en el secreto del diario. Pero premeditadamente nos regala un acercamiento de sus deseos: amor y escritura. Para ello se cuida de no esconder la realidad de sus vagabundeos nocturnos en el mundo de la homosexualidad.

\subsection{Estructura y formas escriturales en Poupée Bella}

La escritura entrecortada que la caracteriza es aún más evidente en este libro que adopta la forma fragmentaria del diario personal, fragmentación que le permite huir de toda tensión compositiva ${ }^{12}$. La forma discontinua provoca una sensación de desmoronamiento, que parece querer anclarse formalmente en la numeración de fragmentos. La fluctuación entre el presente de la escritura, implícito en un diario, y los estratos del pasado, sugieren una sensación de escritura en eco, tanto dentro de PB como en otras obras de la autora. Aquí, sus deseos más secretos y sus deambulaciones nocturnas permiten que la escritura, el "decir", abra el camino de la consciencia. La aceptación de su identidad sexual transforma la noche en agente de deseo; es una frontera múltiple en la que se afrontan su yo, su mundo diurno, el deseo y la fuerza de la escritura. Gracias a ese

11. Actualmente, el término autoficción se aplica a todo tipo de relatos en primera persona en los que se asocia realidad y ficción. Como indica Erman (2010), "il constitue un genre pour le moins indécis [...] qui s'inscrit, sans nul doute, dans une certaine tradition française du récit égotiste".

12. Estamos frente a una forma particular de relato. Para G. Rannaud (1978: 286), el diario íntimo ofrece a la literatura una forma, la de la ruptura, de la discontinuidad, de la fragmentación del discurso; según su percepción, éste podría ser el paso de una literatura del enunciado a una literatura del hic et nunc, del maintenant je. 
punto de sujeción fundamental advierte que el deseo nocturno entraña el peligro de alejarse de ella.

\subsection{El mundo diurno frente al mundo nocturno}

Novela, relato autobiográfico o diario, PB se basa estructuralmente en una división espacial irregular, en el que las pinceladas diurnas adquieren un relieve especial. Esos momentos repetitivos, esas visitas diurnas a sus amantes, como paradas momentáneas en la fugacidad de los contactos nocturnos, ocupan amplios fragmentos, y tienen el poder de borrar los recuerdos sulfurosos de la noche: "Je ne me souviens pas de mes nuits" (PB: 104). Así ocurre con Mikie cuando se recorta su silueta fuera del Milieu des Filles:

Je suis écrasée par les tours, j'ai le vertige du ciel quand je renverse la tête.

Nous sommes loin du Milieu des Filles.

Les façades grises des tours, toutes les vies se tiennent là, bien au-dessus de la terre, bien loin de Paris.

[...]

De Créteil au Milieu des Filles, il y a une éternité (PB: 8889).

Dos figuras se asocian directamente al día: Julien y Marion. Marion es la imagen luminosa del pasado, varada en un mundo positivo bañado por el sol; el de su infancia y juventud, al borde del mar, paraíso perdido de los veranos infantiles: "Elle aimait le soleil de son jardin, elle aimait les vagues blanches, elle aimait ma voix au téléphone, elle aimait s'endormir dans mes bras. Je ne suis plus de cette terre-là. Je ne suis plus de cette mémoire" (PB: 72). Recuerdo asociado a su juventud, que cubre con una luz casi mítica la resaca de sus noches: “Quand je m'endors, c'est toujours l'image de Marion qui vient sur les autres, qui emporte ma nuit. Je la serre dans mes bras. Je deviens mon propre amour" (PB: 55). Su presencia fantasmal es cada vez más frecuente; el deseo no consumado se superpone a sus amores pasajeros, y cada chica será su sustitutivo:

\section{$1^{\text {er }}$ octobre}


Je retrouvais Marion, tous les étés. Dans la nuit je pense à elle.

Marion est comme une maladie. Je la cherche dans les corps et dans la voix des autres. Il y a un relais amoureux. Il y a une brume amoureuse aussi. Je sais et je fais semblant de ne pas savoir (PB: 44).

3 octobre

J'ai encore le numéro de téléphone de Marion. J'appelle, parfois, dans la nuit. Je ne reconnais jamais sa voix (PB: 45).

La figura ambivalente de Julien recuerda a Amine ${ }^{13}$. Entre el día y la noche, ese otro situado entre realidad y ficción permite observar una constante de la escritura de Bouraoui: la busca del yo a través del doble ${ }^{14}$. Consciente de ello, Bouraoui traslada al diario de PB esa presencia: "Nous cherchons un sosie, toujours. Nous cherchons le double de nous-mêmes" (PB: 52).

A medida que avanza la redacción del diario, diríase que los días y los meses se alargan, como si el decirse se hiciera más fácil. Enero de 1989 ocupa excepcionalmente 18 páginas. Pero el alejamiento de Julien y la ruptura con Françoise hacen que el retorno al mundo nocturno del deseo impongan de nuevo las frases cortadas a cuchillo, breves y escuetas. El enunciado minimalista, los intersticios entre lo dicho y lo no-dicho se enmarañan en el torbellino de los días:

\section{5 avril}

Elle m'embrasse dans la lumière bleue du Rex.

18 avril

Je viens de l'écriture.

20 avril

13. "Chacun cherche Amine. Toute sa vie. Par tension. Chacun cherche ce visage. Ce paradis. Chacun cherche ce regard. Cette folie. De se reconnaître. De se contempler. De se doubler. Amine est le rêve du lien perdu. De l'innocence. Du bonheur. Algérien. Amine est la part manquante. Amine est la tristesse qui finit l'été. Amine est le prénom de ma vraie vie" (GM: 166).

14. B. Didier (1981: 27-28) al hablar de las “œuvres lesbiennes”, subraya cómo las mujeres expresan sus pulsiones homosexuales a través de la presencia de "une sœur, une confidente, une amie proche ou lointaine qui lui sert de miroir, certes, mais dont elle est prête aussi à devenir miroir". En el caso que nos ocupa, el doble, llámese Amine o Julien, es una figura recurrente, un muchacho homosexual que se convierte en espejo perfecto. Únicamente el encuentro de su doble exacto feminizará esa imagen, l'Amie de MMP. 
Connaissez-vous Françoise?

22 avril

Elle dit: J'ai dansé toute la nuit.

24 avril

Immense peur de retomber dans le Milieu des Filles, d'attendre et de chercher un visage.

Il y a une tentation du refus d'aimer, comme du refus d'écrire.

Je veux être à la fin de ma nuit.

Julien disait qu'il n'avait pas peur de la mort

Au Kat, les filles se battaient parfois avec des tessons de bouteille (PB: 120).

Bella, en su devenir homosexual, siente un profundo malestar: el peligro que suponen sus escapadas para cumplir con su voluntad última, la escritura. El relato se estructura partiendo de líneas paralelas: la entrada en el Milieu des Filles, la escritura como necesidad íntima, la eterna búsqueda de sí misma. El lector es testigo de la construcción-deconstrucción de la realidad. Su yo multiforme es por fin indivisible; la yuxtaposición del primer amor, ideal luminoso, con la noche de su presente, le permiten afirmarse en la escritura, convertida en sólida base de su personalidad:

Je rêve d'un livre parfait, je rêve d'un amour parfait; l'un ne va pas sans l'autre.

Toute la vie à écrire, toute la vie à se souvenir de l'amour.

Marion est revenue, dès le Milieu des Filles. Souvent je crois l'avoir trahie. Je ne pensais pas à cette vie-là, avant. Je ne pensais pas à cette chute. J'ai le vertige à l'intérieur de moi-même. L'écriture est un pardon (PB: 60).

\section{MES MAUVAISES PENSÉES, EL FINAL DE UNA BÚSQUEDA}

El fin de su búsqueda tiene su epílogo en MMP. La multiplicidad de esta autora de fronteras es, en realidad, un enfrentamiento constante con las prohibiciones, hasta la aceptación final cumplida en este relato. Pensamientos que, según la escritora-o narradora, pues seguimos inmersos 
en la escritura autobiográfica-, son pulsiones negativas:

Avant j'écrivais dans ma tête, puis j'ai eu les mots, des spirales de mots, je m'en étouffais, je m'en nourrissais; ma personnalité s'est formée à partir de ce langage, à partir du langage qui possède. Je n'ose plus me regarder dans le miroir, je ferme les chambres de notre appartement à clé, je cache les couteaux, je dors seule, j'ai si peur de faire du mal à l'Amie (MMP: 10).

Estas palabras revelan una vez más las características de los títulos anteriores: la escritura, el yo, el otro. Ese otro es ahora femenino: 1'Amie, prueba de que Bouraoui ha hallado lo que buscaba. Pero su yo fracturado, pese a todo, sigue presente. Los mismos recuerdos enriquecidos con otras aportaciones, la relación con la familia, la Argelia perdida. Esa pérdida, herida permanentemente abierta, subraya su fisura identitaria y permite ver cómo en los tres libros, en los que expresa su yo más íntimo, la temática común revela su fragilidad individual y su empeño en seguir adelante. Esa voluntad se yergue triunfante en MMP, al llegar al desligamiento de sí misma. Aunque siguiendo la senda de los relatos anteriores, aquí la escritura carece de toda traba y de todo respeto, sobre todo a los cauces habituales del relato autobiográfico.

Dejando salir la lava de su volcán interior ante el receptor de su discurso -el psiquiatra-, brinda también una confesión: "Quand je viens vous voir, je garde l'idée d'une confession” (MMP: 286). El largo monólogo, una psicoterapia delirante, ese yo aparentemente anónimo que se desnuda ante el terapeuta, escenifica una ficcionalización del elemento autobiográfico, al no poder deslindar el lector la verdad de la alucinación y de la imaginación:

il a fallu reconstituer des souvenirs que j'avais brûlés, je me tiens sur des cendres, je marche dans le vent, je porte un voile, je viens d'une enfance romanesque. Mon travail d'écriture est aussi un travail de faussaire. Il n'y a que ma vérité vous savez, il n'y a que mon interprétation des choses (MMP: 206). 
Examinemos ahora del yo al otro, así como la ambiguëdad del receptor. La elección de otro como receptor pudiera indicar un fallo en esa construcción personal, como lleva a pensar la descripción de sus malos pensamientos; pero el silencio de ese receptor permite que los lectores nos apropiemos de ese vous y nos sintamos destinatarios directos de sus palabras:

Dans mes mauvaises pensées, ily a la vision de cette peau que j'ouvre au couteau et de ces viscères que je déchire comme du tissu fin, il y a des mots aussi, que j'ai peur d'entendre: entailler, dépecer, saigner. Dans mes mauvaises pensées, il y a l'obsession de l'intérieur, qui est peut-être le symbole du secret à porter, mais un secret si grand que personne n'en connaît la vraie teneur, c'est un secret-fantasme, qui grossit de génération en génération, c'est le secret de toutes les petites peurs, c'est aussi pour ce secret que je viens vous voir, que je vous supplie, dans ma tête, puisque je contrôle encore mes larmes (MMP: 124).

En esa suerte de confesión ${ }^{15}$ hallamos los mismos elementos fundadores de los relatos anteriores. Y una vez más se repite su miedo más profundo, el de perder la escritura, su pilar vital. Pero su estabilidad brota bajo dos aspectos nuevos: la aceptación definitiva de su homosexualidad, y el encuentro de su doble perfecto, l'Amie: 'c'est ce regard qui garde notre jeunesse, nous contemplons le monde avec les mêmes yeux" (MMP: 145). La Amiga permite la unión entre el amor y la escritura, siendo ese nuevo doble el espejo positivo que le permite desarrollarse tanto personal como escrituralmente:

Nous refaisons le monde, oui, des nuits entières, nous avons le langage pour nous; nous avons les mots, toutes les deux, le langage vient, libre, [...] nous parlons d'amour, nous parlons de chansons, nous parlons de mes livres, de mon écriture qui fait pleurer parfois l'Amie, il y a cette phrase

15. Maingueneau (2004: 197-210) habla de la dramaturgia que se pone en marcha en el análisis del discurso cuando el autor quiere singularizarse dentro de la "escena genérica" de lo que se ha dado en llamar autoficción, y las denomina "escena de palabra" y "escenografía". 
d'elle: "Tu écris en mineur", il y a ce mot de mon éditeur: "Elle est votre meilleure lectrice" (MMP: 145-146).

\section{CONCLUSIÓN}

Por fin, la búsqueda de sí misma, tras diversas formas autobiográficas de expresión, parece terminar. MMP es el relato de una vida compartida, la conclusión gracias al encuentro del doble perfecto, de su otro yo. Diciéndose y exponiéndose, Bouraoui se acepta. La intuición de la escritura como lugar de paz y de lucha a un tiempo brota continuamente de ese manantial de palabras en el que hasta entonces se ocultaba una identidad geográfica y físicamente quebrantada. De GM, autobiografíaautoficción, y PB, diario íntimo que se exhibe, pasamos al manar incesante de la palabra, al terreno autobiográfico teñido de autoficción en MMP, que se anuncia como novela. Palabras que desbordan el alma y que le permiten dominar sus miedos gracias a una escritura en la que la biografía siempre se revela, en pasado o en presente. Y ello utilizando diversas formas del discurso autobiográfico para desvelarse al lector.

El exceso puede resultar impúdico, pero en realidad refleja cómo se disipan gradualmente las fronteras de la, durante tanto tiempo, recatada especificidad femenina. Tras siglos de anulación, el gesto autobiográfico puede tomar en manos de la mujer formas diversas, como Bouraoui permite entrever. A modo de un estallido fragmentador, la escritura del yo, expresada en textos autobiográficos, esparce en la escritura pedazos de la infancia, o fundiendo autoficción y realidad. Es una ruptura enriquecedora de los límites de la autobiografía, por definición unificadora, en que confesión no está reñida con omisión, selección o elipsis, ni con el uso de formas de escritura adyacentes, unificadas en el encuentro del yo.

\section{REFERENCIAS BIBLIOGRÁFICAS}

ADAM, J.-M. (1985). Le texte narratif. París: Nathan.

BACHELARD, G. (1981). La poétique de l'espace. París: P.U.F. 
BOURAOUI, N. (2000). Garçon manqué. París: Stock. (2004). Poupée Bella. París: Stock. (2005). Mes mauvaises pensées. París: Stock.

$\overline{\mathrm{COH}}$, D. (1981). La Transparence intérieure. París: Seuil.

CORDESSE, G. (1988). "Narration et focalisation". Poétique 76, 487-497. DURAND, G. (1969). Les Structures anthropologiques de l'imaginaire. París: Bordas.

ERMAN, M. (2010). "D'un simulacre l'autre: pastiches d'autofictions". Modèles linguistiques 61, http://ml.revues.org/184. DOI: 10.4000/ $\mathrm{ml} .184$ [01/07/2017].

HERMETET, A.-R. \& PAUL, J. M. (dir.) (2016). Écritures autobiographiques. Entre confession et dissimulation. Rennes: Presses Universitaires de Rennes.

LEJEUNE, Ph. (2005). Signes de vie. Le Pacte autobiographique 2. París: Seuil.

MAINGUENEAU, D. (2004). "La situation d'énonciation, entre langue et discours". En Dix ans de S.U.D., 197-210. Rumanía: Editura Universitaria Craiova.

MILLY, J. (1992). Poétique des textes. París: Nathan.

RANNAUD, G. (1978). "Le journal intime: de la rédaction à la publication. Essai d'approche sociologique d'un genre littéraire". En Le Journal intime et ses formes littéraires, V. del Lito (dir.), 277-287. Ginebra: Droz.

Recibido el 17 de junio de 2017.

Aceptado el 15 de septiembre de 2017. 